\title{
Nutrition and oral health in childhood
}

\section{Desislava Dimitrova}

\author{
Department of Pediatric Dentistry, Faculty of Dental \\ Medicine, Medical University - Varna;
}

\begin{abstract}
Nutrition is a key factor for the proper growth and development in children. The aim of this review is to see over and analyse the current scientific evidences on relationship between nutrition and oral health in childhood. Nutrient intake has been shown to affect the growth and development of orofacial structures and may be a major factor in the appearance of the dental diseases. On the other hand, impairment of the function of oral structures and tooth loss may be the cause of incomplete nutrition. The assessment of children's diet should be part of the day-to-day practice of the dentist in order to provide better prophylaxis and appropriate conditions for balanced nutrition.
\end{abstract}

\section{Keywords: nutrition, childhood, oral health}

\section{Background}

Nutrition is a vital life process for every human organism. Through the acceptance, processing and utilization of food, the necessary energy and substances are provided for the establishment and renewal of the cells and tissues and for the realization and regulation of vital functions $(1,2)$.

Disturbances in the orofacial structures and normal chewing function have a negative impact on the processes of nutrients intake which is vital for growth and development in childhood. On the other hand, unbalanced nutrition can also adversely affect oral structures.

The aim of this review is to see over and analyse the current scientific data on the relationship between nutrition and oral health in childhood. From December 2017 to September 2018, an electronic search 
in databases - Google, PubMed, Lilac, keyword "nutrition", "childhood", "oral health" was conducted. The resulting literature data is subjected to a critical analysis, the results from which are presented in the main part of the review.

\section{Results}

Full nutrition is a key factor for proper growth and development in children. The specific nutritional and energy needs of this age are due to the high intensity of the metabolic processes and the continuous formation of tissues (3).

The relationship between nutrition and oral health is scientifically justified $(4,5,6)$. The intake of nutrients affects the development of orofacial structures and oral mucosa and can be major factor in the occurrence of dental diseases such as caries, enamel defects, erosions and periodontal diseases. On the other hand, impairment in the function of the oral structures and tooth loss can cause pain and discomfort in eating different foods, reduced chewing ability, and inability for proper nutrition.

Often the first signs of malnutrition and lack of vitamins (mainly vitamin A and B) are the manifestations on the oral mucosa. There is a characteristic clinical picture of glossitis, stomatitis, angular cheilitis and others. (7). Epidemiological studies $(8,9)$ show that the risk of developing oral cancer decreases with increased consumption of fruit and vegetables due to the high content of vitamin $\mathrm{C}$ and its antioxidant and protective properties.

Nutrition can affect dental structures by two mechanisms (10). After absorption of nutrients, they realize endogenous effects on the teeth before they come in the mouth. This concerns dental germination, organic matrix formation, and mineralization processes. As a result of unbalanced dietary intake, enamel and dentin hypoplasia, fluorosis, reduced number of teeth, alteration in the shape of teeth, change in odontoblastic differentiation, pulp alterations, etc. may occur.

According to Alvarez et al. (11) and Psoter et al. (12) chronic early childhood malnutrition can cause a slow tooth breakthrough and replacement and an increased risk of developing caries. The resorptive action of the food is after the tooth appeared in the mouth and is associated with the creation of a cariogenic or caries-protective oral environment (10). The exogenous influence of food on dental structures can cause dental diseases and dental erosions. Studies (13) show that increased intake of high acid foods and beverages increases the chemical destruction of hard tooth tissues.

The risk of developing caries in children is directly related to the frequency and type of the meals. Frequent intake of high carbohydrate foods results in lower $\mathrm{pH}$ in the dental plaque, increased acid production by microorganisms and demineralization of dental tissues (14). The type and consistency of carbohydrates consumed also determines the caries risk. Some foods are more retentive to the dental surfaces and facilitate the formation of a plaque. Low molecular mono- and disaccharides are yet degraded in the cavity under the action of the amylase enzyme and dramatically increase the cariogenic situation (15).

Evidence of the effect of the frequent and high sugar consumption, carbohydrate retentivity and the time of ingestion on caries development is the Vipeholm study (16). The results show that additional sugars in 
food significantly increase caries activity, but the degree is strictly dependent on the consistency of carbohydrates themselves. The risk of caries is higher when the consumed sugar or confectionery is out of the main daily meals and is in a form requiring extra time in the oral cavity (lollipops, candy, etc.)

According to a Tinanoff study (17), the body can successfully counteract acid attacks. When receiving relatively small amounts of sugars, and in the absence of intermediate meals, adequate conditions and sufficient time to carry out re-mineralization processes with substances coming from saliva (calcium, phosphorus) are created.

The results of Bakardzhiev et al. (18) study testify that $34.6 \%$ of children eat 4 times and $15 \%-5-6$ times a day. Concerning preferred carbohydrate products $70.66 \%$ of the students mention chocolate, $40 \%$ wafer, $23 \%$ - candy, $14 \%$ - biscuits, $8.67 \%$ - cakes and pastes. Although chocolate is referred to as favorite by most of the children, it is less cariogenic due to the protective action of cocoa and milk in it.

An example of the relationship between long-term carbohydrate consumption and bad eating habits is "early childhood caries " (19). Prolonged night meals lead to long periods of high acidity, which damages less mineralized deciduous teeth. According to researches $(20,21), 86 \%$ of children with caries of the upper frontal incisors fall asleep while they are fed from a bottle with pacifier.

According to scientific studies (22), foods and beverages such as milk, dairy products and fluorinated water have a caries-protective effect. These products increase the amount of calcium, phosphorus and fluorine in the plaque, stimulate salivation, reduce the harmful effects of carbohydrates, and provide the processes of remineralization of acid attacked tooth surfaces.

It is known $(23,24)$ that disturbances in the dental rows, partial or total lack of teeth impair chewing efficiency. This leads to restriction of the intake of certain foods, incomplete initial processing of nutrients, development of diseases of the digestive system and others.

The application of prosthetic treatment in children and adults may also affect the diet (25). Inappropriately adapted constructions can lead to pain, lack of chewing ability, oral mucosal infections and taste changes. All of this results in incomplete dietary intake, changes in the weight and in the psychological status. Patients prefer mushy high-carbohydrate food, which is deficient in vitamins and minerals needed for the growing and exchanging processes in infancy.

Contemporary scientific studies $(26,27)$ analyze the relationship between chronic dental diseases associated with carious destruction of the dentition and inadequate nutrition of children.

The presence of dental diseases, according to Sheiham (28), can negatively affect children's growth and development processes. The author states that untreated carious lesions cause pain and discomfort during meals. There are deviations in the quality and quantity of the ingested nutrients - patients are selfrestricted to several types of foods consumed, which usually do not meet the physiological needs of the body at this age.

Clarke et al. (29) show that all children affected by early childhood caries have signs of malnutrition - their weight is below the normal assumed for children at the same age. The results of Ngoenwiwatkul study (27) show that the distribution of the caries in 212 early-aged children is $80.2 \%$, and nearly half of the children surveyed (45.8\%) are at risk of malnutrition. 
Of scientific interest is the study of Asc et al. (30), the aim of which is to track the changes in the weight of small patients before and after treatment of the early childhood caries. The results show that the affected children weigh less than $80 \%$ of the recommended age weight. In a period of an average of $1.4 \pm 0.4$ years, after the defects are recovered, a "catch-up phenomenon" was observed for the healed children. In a comparative assessment with a control group in the same study, an increasing weight of average $4.6 \mathrm{~kg}$ during the follow-up period was reported for the children with early childhood caries, while in healthy kids the body weight gain was $2.5 \mathrm{~kg}$.

Scientific studies $(31,32)$ also testify for improving the indicators of growth and development in children after treatment and restoration of the deciduous teeth affected by caries and its complications. There is an increase in the weight of the children and attaining values corresponding to age-appropriate. According to Sheiham (28), this is due to the recovering of appropriate conditions for a normal quantitative and qualitative intake of nutrients.

\section{Conclusion}

The conducted literary analysis shows an unfavorable trend towards nutrition of the children with disturbances in oral structures. There are statistically significant relationships between the presence of multiple caries and the established low body mass index of children. Conducting treatment and restoring the shape and size of injured teeth positively affects the quantitative and qualitative intake of nutrients, resulting in weight gain and formation of the "catch-up phenomenon." That is why examining and assessing dietary intake in children should be part of dental treatment as it provides prerequisites for prevention of malnutrition, result of disturbed dental structures and promotes balanced nutrition for normal growth and development in childhood.

\section{Acknowledgements:}

The author expresses his deep gratitude to Associate Professor Mariana Dimova-Gabrovska for the assistance and support provided during the research.

\section{References}

1. Vitanova L, Gurchev R. Physiology of the human (in Bulgarian). Publisher: Arso 2015 book.

2. Konstantinova D. Study of chewing function in experimental and clinical conditions. PhD thesis. Varna 2016. (in Bulgarian)

3. Konstantinova D, Dimova M, Naydenova D: Impact of food preferences on the development of pathological changes in the masticatory apparatus in young patients, Journal of IMAB, 2016, 22, 3, 1230-1234

4. Rashkova M, Mitova N, Lozanov B, Russeva S, Mateva A, Zhegova G. Saliva metabolite analysis - products of the protein metabolism in the saliva and oral pathology in children. Problems of Dentistry 2014; 40 (2): 13-21. (in Bulgarian)

5. Andreeva R., Arnautska H, Georgieva M, Dimitrov E, Dimova-Gabrovska M. Importance of the carious activity of the parents in connection with the premature tooth loss of their children, Medinform, 2016, 1, 404-408 
6. Korchagina $\mathrm{V}$. Methods of increasing the efficiency of restorations of primary teeth in small children. Clinical Dentistry. 2005; 2: 4-9. (in Russian)

7. Kristeva A. Anemia and nutritional deficiencies in dental practice. Varna Medical Forum 2016; 5 (2): 197-203. (in Bulgarian)

8. McLaughlin J, Grindley G, Block G, Winn DM, Preston-Martin S, Schoenberg JB. Dietary factors in oral and pharyngeal cancer. J Natl Cancer Inst 1988; 80(15): 1237-1243

9. Morse DE. Oral and pharyngeal cancer. In: In: Touger-Decker R, Sirois D, Mobley C, editors. Nutrition and oral medicine. New Jersey: Humana Press; 2004; 205-221

10. Peneva M, Tzolova E, Kabakchieva R, Rashkova M. Prophylaxis of oral diseases (in Bulgarian). Publisher: East-West, Sofia 2009.

11. Alvarez J, Lewis C, Saman C, Caceda J, Montalvo J, Figueroa M, Izquierdo J, Caravedo L, Navia J. Chronic malnutrition, dental caries, and tooth exfoliation in Peruvian children aged 39 years. Am J Clin Nutr 1988; 48(2): 368-372

12. Psoter W, Gebrian B, Prophete S, Reid B, Katz R. Effect of early childhood malnutrition on tooth eruption in Haitian adolescents. Community Dent Oral Epidemiol 2008; 36(2): 179-189

13. Jarvinen V, Rytomaa I, Heinonen OP. Risk factors in dental erosion. J Dent Res 1991; 70(6):942-947

14. Alvarez J, Lewis C, Saman C, Caceda J, Montalvo J, Figueroa M, Izquierdo J, Caravedo L, Navia J. Chronic malnutrition, dental caries, and tooth exfoliation in Peruvian children aged 39 years. Am J Clin Nutr 1988; 48(2): 368-372

15. Damyanova D. Clinical-statistical study of caries of the deciduous teeth in children from 4 to 6 years of age. Varna Medical Forum. 2017 June; 2 (6): 25-28. (in Bulgarian)

16. Gustafsson B, Quensel CE, Swenander-Lanke L, Lundqvist H, Grahnen H, Bonow B, Krasse B. The Vipeholm dental caries study. The effect of different levels of carbohydrate intake on caries activity in 436 individuals observed for five years. Acta Odont Scand 1954; 11: 232-236

17. Martos J, Nascimento CN, Collares KF, Silveira L. Trauma in permanent central incisor with crown fracture treated by direct restoration. J Pediatr Dent 2013; 1(1): 24-26

18. Bakardzhiev P, Toneva N, Georgieva M, Peneva M, Trade S. Knowledge of nutrition and oral hygiene of children in school age. Problems of Dentistry 2013; 39 (1): 19-23. (in Bulgarian)

19. Touger-Decker R, Mobley CC. Position of the American Dietetic Association: Oral Health and Nutrition. J Am Diet Assoc 2003; 13(5): 615-625

20. Kaste LM, Gift HC. Inappropriate infant bottle feeding. Status of Healthy People 2000 Objectives. Arc Pediatr 1995; 149(7):786-791

21. Powell D. Milk... is it related to rampant caries of the early primary dentition? J Calif Dent Assoc 1976; 4(1): 58-63

22. Tinanoff N, Palmer C. Dietary determinants of dental caries and dietary recommendations for preschool children. J Public Health Dent 2000; 60(3):197-206

23. Mojon $\mathrm{P}$, Budtz-Jorgensen $\mathrm{E}$, Rapin $\mathrm{CH}$. Relationship between oral health and nutrition in very old people. Age and Ageing 1999; 28(5):463-468

24. Joshipura K, Willett W, Douglass CW. The impact of edentulousness on food and nutrient intake. J Am Dent Assoc 1996; 127(4):459-467

25. Ritchie C, Joshipura K, Hung HC, Douglass Cw. Nutrition as a mediator in the relation between oral and systematic disease: associations between specific measures of adult oral health and nutritional outcomes. Crit Rev Oral Biol Med 2002; 13(3): 291-300

26. Naidoo S, Myburgh N. Nutrition, oral health and the young child. Matem Child Nutr 2007; 3(4): 312-321

27. Ngoenwiwatkul Y. Leela-Adisorn N. Effects of dental caries on nutritional status among firstgrade primary school children. Asia Pac Public Health 2009; 21(2): 177-183

28. Sheiham A. Dental caries affects body weight, growth and quality of life in pre-school children. Br Dent J 2006; 201(10): 625-626

29. Clarke M, Locker D, Berall G, Pencharz P, Kenny D, Judd P. Malnourishment in a population of young children with severe Early childhood caries. Pediatr Dent 2006; 28(3): 254-259 
30. Acs G, Shulman R, Wai Ng M, Chussid S. The effect of dental rehabilitation on the body weight of children with early childhood caries. Pediatr Dent 1999; 21(2): 109-113

31. Acs G, Lodolini G, Shulman R, Chussid S: The effect of dental rehabilitation on the body weight of children with failure to thrive: case reports. Compend Contin Educ Dent. 1998, 19(2): 164-171.

32. Malek Mohammadi TM, Wright CM, Kay EJ: Childhood growth and dental caries. Community Dent Health. 2009, 26(1): 38-42.

\section{Corresponding author:}

Desislava Dimitrova,

Department of Pediatric Dentistry,

Faculty of Dental Medicine,

Medical University - Varna,

Email: desislavvva23@gmail.com 